\title{
Presença de Peptostreptococcus indolicus em bula timpânica de cão com otite média
}

\author{
Carlos Artur Lopes Leite ${ }^{1}$
}

DOI: https://doi.org/10.35699/2447-6218.2021.32519

\begin{abstract}
Resumo
A otite média é definida como uma inflamação da orelha média. Em cães, essa condição é uma das causas mais comuns na manutenção de otite externa recorrente. Tanto bactérias aeróbicas como anaeróbicas estão presentes na bula timpânica doente, sendo que em algumas circunstâncias, torna-se difícil determinar qual o papel que estes microrganismos ali exercem. Apesar de a microbiota aeróbica ser frequentemente estudada em cães com otopatias, poucos dados estão disponíveis sobre os microrganismos anaeróbicos estritos presentes nas orelhas destes pacientes. Neste relato é revelado o isolamento da bactéria anaeróbica Peptostreptococcus indolicus no exsudato de um cão adulto da raça São Bernardo com otite média crônica bilateral, se tratando da primeira descrição na literatura veterinária relacionada à presença desta espécie bacteriana em otite média canina. Com base neste achado, é sugerido que bactérias anaeróbicas como $P$. indolicus podem estar relacionadas ao processo infeccioso da orelha média em cães.
\end{abstract}

Palavras-chave: Bactérias anaeróbicas. Dermatologia. Otologia.

\section{Presence of Peptostreptococcus indolicus in tympanic bulla of dog with otitis media}

\begin{abstract}
The otitis media is defined as an inflammation of the middle ear. In dogs, this condition is one of the most common causes of maintaining recurrent otitis externa. Both aerobic and anaerobic bacteria are present in the diseased tympanic bulla, and in some circumstances, it becomes difficult to determine what role these microorganisms play. Although the aerobic microbiota is frequently studied in dogs with ear diseases, little data is available on the strict anaerobic microorganisms present in the ears of these patients. In this report, the isolation of the anaerobic bacteria Peptostreptococcus indolicus is revealed in the exudate of an adult Saint Bernard dog breed with bilateral chronic otitis media, being the first description in the veterinary literature related to the presence of this bacterial species in canine otitis media. Based on this finding, it is suggested that anaerobic bacteria such as $P$. indolicus may be related to the infectious process of the middle ear in dogs.
\end{abstract}

Key words: Anaerobic bacteria. Dermatology. Otology.

${ }^{1}$ Faculdade de Zootecnia e Medicina Veterinária, Departamento de Medicina Veterinária, Universidade Federal de Lavras (UFLA). Lavras, MG. Brasil. http://orcid.org/0000-0002-0551-9317

*Autor para correspondência: caca@ufla.br

Recebido para publicação em 15 de março de 2021. Aceito para publicação em 26/de junho de 2021.

e-ISSN: 2447-6218 / ISSN: 2447-6218. Atribuição CC BY. 
Leite, C. A. L.

\section{Introdução}

A otite média (OM) é definida como uma inflamação da orelha média, causada por infecção bacteriana, disseminação hematógena ou mesmo uma extensão de quadros infecciosos da nasofaringe através da tuba auditiva (Bruyette e Lorenz, 1993; Little et al., 1991). Em seu estado crônico, a OM é uma afecção potencialmente destrutiva caracterizada por alterações variáveis e recorrentes do epitélio da bula timpânica e estruturas ósseas adjacentes (Papastavros et al., 1986). Essa condição é comum em pacientes com otite externa (OE) crônica não responsiva aos tratamentos clínicos de rotina, constituindo-se em um dos maiores entraves na cura clínica das otopatias em cães (Brook e Van de Heyning, 1994).

A OM pode ser primária (rara em cães, como citam Bruyette e Lorenz, 1993; Gotthelf, 2000) ou, mais frequentemente, secundária, causada por uma extensão de um quadro infeccioso de etiologia bacteriana presente na $\mathrm{OE}$, que avança pelo óstio do meato auditivo até o interior da bula timpânica (August, 1988). A ruptura da membrana timpânica nos quadros de OE pode ser causada pela liberação de proteases bacterianas e lisozimas oriundas de células fagocitárias presentes na região afetada. Mesmo animais com membranas timpânicas hígidas podem apresentar OM (Murphy, 2001), embora não seja o esperado (Little e Lane, 1989).

A microbiota bacteriana dos exsudatos presentes na bula timpânica de cães otopatas tem sido extensivamente estudada (Griffin, 2020; Paterson et al., 2021), porém, faltam dados sobre os microrganismos anaeróbicos estritos possivelmente presentes nesta condição (Gotthelf, 1995). É possível que a caracterização desse grupamento bacteriano, juntamente com o entendimento sobre a relação entre os diversos gêneros de microrganismos com o meio e consigo mesmo, possibilite um avanço maior na área otológica de pequenos animais, já que bactérias e fungos não são considerados fatores desencadeantes de otites, mas sim mantenedores de um processo já instalado (August, 1988).

As bactérias são os microrganismos mais frequentemente isolados em cães com OM (Colombini et al., 2000). Há dois grandes grupos bacterianos em orelhas doentes: aeróbicos e anaeróbicos. Ambos são considerados fatores perpetuantes (August, 1988), pois não causam otopatias de forma direta, mas apenas as mantém. Em otologia humana, está comprovada a natureza polimicrobiana das OM (Brook et al., 1983; Brook et al., 1992; Brook et al., 1998; Koneman et al., 1994; Papastavros et al., 1986). É possível que esta associação entre microrganismos exerça um efeito sinérgico final, diferentemente quando há apenas uma espécie bacteriana envolvida. Apesar de alguns relatos indicarem que 15-35\% dos exsudatos presentes na bula timpânica possam ser estéreis (Soriano, 1997), outras pesquisas comprovam que há resquícios de ácido desoxirribonucleico (DNA) bacteriano neste material (Gok et al., 2001). Este DNA pode ser oriundo de bactérias com baixa viabilidade celular, clamídias, micoplasmas ou mesmo microrganismos ainda não conhecidos (Soriano, 1997).

Nos últimos anos, a microbiota anaeróbica presente no conduto auditivo de cães otopatas vem sendo investigada com maior cuidado, especialmente o grupo de anaeróbios estritos, devido a uma possível ação nas otopatias de pequenos animais (Paterson, 2020). Estas bactérias podem ser divididas em dois grupos: anaeróbicas obrigatórias e aerotolerantes (Koneman et al., 1994). Ainda segundo aqueles autores, as bactérias anaeróbicas obrigatórias (BAO) crescem na ausência de oxigênio livre, mas não se desenvolvem quando incubadas ao ambiente ou em incubadoras com 5-10\% de $\mathrm{CO}_{2}$. Neste grupo podem ser encontradas bactérias obrigatórias estritas, que não crescem na superfície de meios expostos ao $\mathrm{O}_{2}$ atmosférico, e bactérias obrigatórias moderadas, que podem crescer quando expostas ao ambiente com $2-8 \%$ de $\mathrm{O}_{2}$. No grupo das bactérias anaeróbicas aerotolerantes (BAA) estão aquelas que se desenvolvem muito pouco em meios de cultura incubados no ambiente ou em incubadoras com 5-10\% de $\mathrm{CO}_{2}$.

Em medicina não há até o momento uma definição exata do papel que as bactérias anaeróbicas possam exercer na OM (Nwaokorie et al., 2017), porém as pesquisas indicam que estes microrganismos possivelmente mantêm a doença por períodos prolongados (mesmo após a instituição da terapia), conforme relatos de Paterson (2020). Há relatos demonstrando que essas bactérias anaeróbicas estão envolvidas com OM grave em seres humanos (Koneman et al., 1994; Amano et al., 2020), já que no ambiente da bula timpânica (baixa tensão de $\mathrm{O}_{2}$ ), conseguem se desenvolver. É importante ressaltar que as otopatias descritas em seres humanos possuem características que as diferem acentuadamente das encontradas em cães (Gotthelf, 2000). Entretanto, as comparações são inevitáveis, ainda mais quando pouco se conhece sobre o verdadeiro papel da microbiota auditiva anaeróbica no microambiente de cães otopatas.

Há relativamente poucos estudos sobre bactérias anaeróbicas na OM de pequenos animais. No primeiro relato da presença de uma bactéria anaeróbica no ambiente auricular de um cão otopata, isolou-se Clostridium sp (Fraser et al., 1961). Um resultado similar ocorreu em outra pesquisa (Denny, 1973), em que Clostridium sp também foi isolado de cães com OM. Em um estudo posterior utilizando 23 cães com OM crônica bilateral, bactérias anaeróbicas foram encontradas em 1,3\% das orelhas examinadas, porém não foi realizada a classificação taxonômica desses microrganismos (Cole et al., 1998).

A bactéria Peptostreptococcus é um microrganismo anaeróbico estrito, Gram-positivo e não esporulado, que ocorre em pares, tétrades, massas irregulares ou em cadeias. Este gênero foi isolado de abscessos na vesícula urinária (100\%), vagina $(87 \%)$, pênis $(86 \%)$, rins $(83 \%)$ 
Presença de Peptostreptococcus indolicus em bula timpânica de cão com otite média

e uretra (71\%) em seres humanos (Hnatko, 1983). O Peptostreptococcus também foi isolado em outros processos mórbidos, como abscessos periapicais (68\%), ferimentos penianos (66\%) e abscessos das mamas (51\%), além de membranas placentárias de mulheres gestantes, espe- cialmente nos partos prematuros (Hnatko, 1983). Em Medicina Veterinária, este gênero bacteriano foi isolado tanto de animais hígidos quanto doentes, incluindo o ambiente ótico (Quadro 1).

Quadro 1 - Isolamento de Peptostreptococcus sp em Medicina Veterinária de acordo com espécie animal, localização anatômica e quadro patológico.

\begin{tabular}{|c|c|c|c|}
\hline ESPÉCIE & LOCALIZAÇÃO ANATÔMICA & QUADRO PATOLÓGICO & AUTORIA \\
\hline \multirow{5}{*}{ CANINA } & Gengiva & Doença periodontal & Valdez e Vallejo (2020) \\
\hline & Pleura & Piotórax & Maggio et al. (2011) \\
\hline & Coração & Depressão miocárdica pós-sepse & Dickinson et al. (2007) \\
\hline & Ossos & $\begin{array}{l}\text { Osteomielite em pós-cirúrgico de } \\
\text { fixação esquelética externa }\end{array}$ & Carneiro et al. (2001) \\
\hline & Ouvidos & (Animais hígidos) & Shuiquan et al. (2020) \\
\hline \multirow{2}{*}{ FELINA } & Cavidade bucal & Estomatite & Santos et al. (2019) \\
\hline & Pleura & Piotórax & Maggio et al. (2011) \\
\hline EQUINA & Gengiva & Abscesso periodontal & Kern et al. (2016) \\
\hline \multirow{3}{*}{ BOVINA } & Útero & Endometrite & Peng et al. (2013) \\
\hline & Vagina & Vaginite & Husted (2003) \\
\hline & Fígado & Abscessos & Silva (2018) \\
\hline $\begin{array}{c}\text { AVE } \\
\text { (Avestruz) }\end{array}$ & Sistema gastrintestinal & (Animais hígidos) & Marinho et al. (2004) \\
\hline
\end{tabular}

Após a identificação do agente etiológico presente na orelha média de cães otopatas, a escolha do princípio ativo a ser empregado deve basear-se nos testes de sensibilidade aos antimicrobianos (Gotthelf, 2000). Entretanto, tal como descrito por Reig et al. (1992), apesar dos padrões de resistência antimicrobiana de bactérias anaeróbias serem considerados altamente preditivos, não é rotineira a realização dos testes de sensibilidade antimicrobiana com este tipo de microrganismo, dificultando uma escolha adequada da base farmacológica a ser empregada em cada caso. Assim, se torna dificultosa a operação de comparação entre raros estudos que, adicionalmente, utilizam métodos de avaliação diferentes.

O perfil de resistência antimicrobiana (PRA) de P. indolicus é variável de acordo com os poucos relatos disponíveis. Reig et al. (1992) relataram que diferentes cepas mostram diferentes taxas de PRA. Adicionalmente, esses pesquisadores citaram que há pesquisas diversas com o gênero Peptostreptococcus revelando, principalmente, seu PRA para antibióticos dos grupos dos macrolídeos (como a eritromicina) e lincosamidas (como a clindamicina). Nestas avaliações, de métodos microbiológicos que se diferenciam entre si, atestaram-se tanto PRA de baixa ou nula sensibilidade (Concentração Inibitória Mínima, CIM, menor que $1 \mathrm{mg} / \mathrm{mL}$ ) até grande resistência antimicrobiana (CIM maior que $8 \mathrm{mg} / \mathrm{mL}$ ). Ainda segundo estes autores, 62\% das amostras testadas (de um total de 350 cepas) revelaram resistência cruzada entre clindamicina e eritromicina. Já o Comitê Nacional para Padrões Laboratoriais Clínicos (NCCLS, 1990) sugeriu PRA de 26,3\% (para a clindamicina) e 55,2\% (para a eritromicina).

É possível que, seguindo o padrão das BAO, o gênero Peptostreptococcus seja sensível ao metronidazol. Muitos quadros de OM humana são tratados com este nitroimidazólico, já que cerca de um terço da microbiota bacteriana nestes casos é composta por BAO (Jokipii et al., 1978; Jokipii e Jokipii, 1981); logo, é comum a sua utilização na rotina terapêutica da OM humana (Brook e Van de Heyning, 1994; Papastavros et al., 1986; Soriano, 1997).

\section{Relato de Caso}

Foi atendido no Hospital Veterinário do Departamento de Medicina Veterinária da Universidade Federal de Lavras (DMV/UFLA) um cão da raça São Bernardo, macho, idade de cinco anos e dez meses e pesando $63 \mathrm{~kg}$. Seu longo histórico de otopatia se iniciou quando tinha dois anos de idade, com otite externa bilateral recidivante. Neste período foi sendo tratado alternadamente por diversos protocolos terapêuticos específicos para otopatias, sempre com remissões do quadro clínico otopático inicial. 
Leite, C. A. L.

No momento da consulta estava sem qualquer intervenção medicamentosa ou de manejo há pelo menos 30 dias.

Ao exame físico, as alterações observadas clinicamente foram rarefação pilosa em todo o corpo, aumento de tamanho dos linfonodos mandibulares, linfonodos parotídeos reativos, otalgia à palpação das regiões periaural e aural, otorreia mucopurulenta bilateral, com descarga moderada e odor pútrido, estenose mediana dos óstios dos condutos auditivos externos, hiperpigmentação melânica moderada das escafas e concreções ceruminosas dispersas na entrada dos canais verticais.

O paciente foi conduzido para a realização de exames otológicos específicos (otoscopia direta, radiologia convencional, canalografia, citologia auditiva e microbiologia ótica).

No momento da realização dos testes otológicos específicos, o paciente foi submetido à medicação pré-anestésica (MPA) com uma associação de xilazina ${ }^{2} 2 \%$ $(0,5 \mathrm{mg} / \mathrm{kg}, \mathrm{IM})$ e morfina ${ }^{3} 1 \%(1,0 \mathrm{mg} / \mathrm{kg}, \mathrm{IM})$; a indução anestésica foi realizada com tiopental sódico $2,5 \%$ (10,0mg/kg, IV) e a manutenção da anestesia executada com isoflurano $4(1,5 \mathrm{~V} \%)$. Os condutos auditivos foram examinados utilizando-se otoscópio portátil ${ }^{5}$ com cones esterilizados. Neste mesmo momento, o exsudato foi colhido por meio de uma sonda metálica ${ }^{6}$, introduzida através do espéculo otológico, o mais profundamente possível dentro da bula timpânica. Em seguida, o material intracavitário da bula timpânica foi aspirado para uma seringa descartável estéril de $10 \mathrm{~mL}$, sendo imediatamente acondicionada em ambiente anaeróbico para posterior análise microbiológica. Concluída esta etapa, swabs estéreis foram introduzidos o mais profundamente possível na porção ventral de cada bula para confecção de esfregaços da parede do espaço timpânico, se tomando a precaução de evitar a cadeia ossicular e os ramos simpáticos do nervo facial na face dorsomedial do arcabouço ósseo. Por fim, foram realizados os exames radiográficos convencionais (posicionamento oblíquo dorsoventral a $20^{\circ}$ direito e esquerdo e rostrocaudal a $30^{\circ}$ com boca aberta) e contrastado positivo (canalografia, segundo técnica descrita por Trower et al., 1988), utilizando solução radiopaca não iônica ${ }^{7}$ (posicionamento dorsoventral).

Imediatamente após a colheita do exsudato intracavitário, as amostras foram inoculadas em placas de Petri contendo ágar tioglicolato e ágar sangue anaerobiose (em duplicata). As placas foram então acondicionadas em jarra anaeróbica hermética ${ }^{8}$ com gerador químico de

${ }^{2}$ Xilazin $®$, Syntec - Brasil.

${ }^{3}$ Sulfato de morfina injetável 10mg/mL, Hipolabor Farmacêutica - Brasil.

${ }^{4}$ Vetflurane®, Virbac - Brasil.

${ }^{5}$ Diagnostic Set \# 3003®, Gowllands Medical Devices, Ltd - Reino Unido.

${ }^{6}$ Malleable Stylette for Jet Ventilator w/ Luer Lock® $20 \mathrm{~cm}$, Anesthesia Associates, Inc. - EUA.

${ }^{7}$ Omnipaque ${ }^{\circledR}$, GE Healthcare Co., Ltd - China.

${ }^{8}$ Jarra para Anaerobiose ${ }^{\circledR}$, Probac do Brasil Produtos Bacteriológicos Ltda. - Brasil. ambiente anaeróbico ${ }^{9}$, sendo incubadas a $37^{\circ} \mathrm{C}$ por 48 $72 \mathrm{~h}$, de acordo com recomendações de NCCLS (1990). Todos os microrganismos que se desenvolveram nestas condições foram identificados por métodos bioquímicos usuais de rotina utilizados em microbiologia (Koneman et al., 1979; Koneman et al., 1994; Hillier e Moncla, 2007).

Para fins de diferenciação entre BAO (só crescem na ausência de oxigênio) e BAA (crescem tanto na ausência ou na presença de oxigênio), foi realizada replicação das cepas com crescimento positivo em placas de ágar sangue e mantidas em estufa a $37^{\circ} \mathrm{C}$ por $48-72 \mathrm{~h}$ e com tensão de oxigênio ambiente.

A avaliação da sensibilidade antimicrobiana foi realizada em ambiente anaeróbico, como descrito anteriormente para cultura e isolamento de $\mathrm{BAO}$, utilizando o método preconizado por Wilkins e Thiel (1973) através de baterias de microdiluição em caldo infusão cérebro-coração ${ }^{10}$ enriquecido com extrato de levedura 0,5\%. Após dupla testagem, foram anotadas as concentrações inibitórias mínimas para os seguintes antibióticos: ampicilina (AMP), cefotaxima (CTX), cefoxitina (CFO), cloranfenicol (CLO), clindamicina (CLI), eritromicina (ERI), metronidazol (MTZ) e penicilina G (PEN). Para efeitos de análise e comparação de resultados, foram utilizados os dados propostos por Reig et al. (1992) na determinação de CIM para o gênero Peptostreptococcus.

\section{Resultados e discussão}

Ao exame otoscópico, foi detectada ruptura bilateral total da membrana timpânica, além de alterações progressivas do epitélio dos condutos auditivos (horizontal e vertical) sugerindo hiperceratose. Murphy (2001) cita a possibilidade de OM com manutenção da integridade da membrana timpânica, o que não foi encontrado neste estudo. Provavelmente esta condição não ocorreu em função da cronicidade do caso, já que a OM com tímpano íntegro é mais comum nos casos agudos (Little e Lane, 1989).

As projeções radiográficas revelaram alterações no contorno da bula timpânica, proliferação óssea com lise, aumento da radiopacidade intracavitária e deformação do arcabouço timpânico. Estes achados são conclusivos para estabelecer o diagnóstico de OM (Little e Lane, 1989; Little et al., 1991; Gotthelf, 1995). O procedimento de canalografia demonstrou ser útil nos casos em que havia ruptura timpânica sem que fosse revelado pela otoscopia, como preconizado por Trower et al. (1998).

A citologia auditiva revelou acentuada descamação epitelial substanciada pelo excesso de ceratinócitos por campo examinado em ambas as orelhas. A presença de células cuboidais típicas do epitélio respiratório da bula timpânica confirmou a ruptura do tímpano e o quadro instalado de OM média bilateral. Também foi acusada a

${ }^{9}$ Anaerobac $®$, Probac do Brasil Produtos Bacteriológicos Ltda. - Brasil. ${ }^{10}$ Caldo Infusão Cérebro-Coração (BHI) $®$, Prolab - Brasil. 
presença de poucos cocos Gram-positivos e abundância de cordões fibrinosos, este último achado suportando a evolução crônica da síndrome ótica. Estes achados estão de acordo com a descrição de diversos autores para cães otopatas crônicos (August, 1988; Brook et al., 1983, Brook et al., 1992; Bruyette e Lorenz, 1993; Brook et al., 1998).

O P. indolicus foi isolado de ambas as bulas timpânicas. As análises bioquímicas e suas características de cultivo estão dispostas no Quadro 2. De acordo com Hillier e Moncla (2007), os cocos Gram-positivos anaeróbicos normalmente são isolados em conjunto com outros microrganismos, o que pode ser constatado neste trabalho, pois P. indolicus foi isolado em associação com outras bactérias (Pseudomonas aeruginosa e Aerobacter aerogenes).

Quadro 2 - Testes bioquímicos e características de cultivo de Peptostreptococcus indolicus isolado do exsudato da bula timpânica de cão da raça São Bernardo (macho, adulto) com otite média bilateral.

\begin{tabular}{lc}
\hline \multicolumn{1}{c}{ DESCRIÇÃO } & RESULTADO \\
\hline Produção de pigmento negro em ágar tioglicolato & Negativo \\
Produção de coagulase & Positivo \\
Teste do indol & Negativo \\
Redução de nitrato & Positivo \\
Produção de urease & Negativo \\
Fermentação de celobiose & Negativo \\
Fermentação de glicose & Negativo \\
Fermentação de lactose & Negativo \\
Fermentação de maltose & Negativo \\
Fermentação de sacarose & Negativo \\
\hline
\end{tabular}

Apesar de Cole et al. (1998) também terem isolado bactérias anaeróbicas da orelha média, uma comparação mais estreita com os achados deste trabalho não pode ser efetuada, já que aqueles pesquisadores não procederam à identificação dos microrganismos envolvidos.

Os outros dois estudos referentes ao isolamento de bactérias anaeróbicas da bula timpânica de cães otopatas (Denny, 1973; Fraser et al., 1961) também não servem para efeito de comparação com esta pesquisa, já que se referem a outro gênero bacteriano (no caso Clostridium).

O significado da presença de $P$. indolicus em OM deve ser considerado com muita cautela. A probabilidade desta espécie representar uma contaminação ambiental é mínima, em grande parte devido ao isolamento duplo de bulas diferentes (uma de cada orelha, apesar de serem do mesmo animal). Este gênero de bactéria anaeróbica está relacionado com quadros graves de OM em seres humanos como afirmado por Hnatko (1983), mas nenhuma informação foi fornecida para cães. É possível que o $P$. indolicus possa assumir um papel importante como um fator perpetuante em cães com OM, em especial pelo metabolismo diferenciado, com consequente produção de substâncias potencialmente nocivas ao ambiente auricular. De relevância clínica também se deve citar a possibilidade deste microrganismo disseminar-se para diversos órgãos corporais - como o cérebro, causando meningite e óbito em seres humanos (Jokipii e Jokipii, 1981; Gok et al., 2001).
O PRA obtido está representado na Figura 1. Utilizando como referência a pesquisa de Reig et al. (1992), se pode verificar que os antibióticos pertencentes ao grupo dos penicilínicos (ampicilina e penicilina G) e das cefalosporinas (cefotaxima e cefoxitina) foram mais eficientes in vitro contra $P$ indolicus. Estas classes de antibióticos têm sido mais utilizadas na terapia da OM canina, principalmente em função do seu amplo espectro antibacteriano, baixo custo, facilidade de administração e reduzido índice de efeitos colaterais.

Pode-se ressaltar nesta pesquisa a baixa eficácia in vitro dos antibióticos clindamicina, eritromicina e metronidazol. A clindamicina, um antibiótico do grupo das lincosamidas, é utilizada na terapia sistêmica de otopatias, principalmente por causa de sua grande lipossolubilidade. Entretanto, face ao extenso perfil de resistência por parte da microbiota do conduto doente, seu uso clínico vem caindo em desuso (Gotthelf, 2000).

O metronidazol, um composto azólico de propriedades antibacterianas fracas, não possui muita valia nos casos de $\mathrm{OE} / \mathrm{OM}$ em medicina veterinária (Colombini et al., 2000). Este antibiótico possui uma ação comprovada sobre bactérias anaeróbicas (Koneman et al., 1979; Koneman et al., 1994), porém, neste estudo, sua eficácia foi baixa. Alguns pesquisadores relatam que o metronidazol possui boa ação contra anaeróbios presentes na orelha média de pacientes humanos (Jokipii e Jokipii, 1981; Jokipii et al., 1978), sendo comum a sua utilização na rotina clínica otológica (Brook e Van de Heyning, 1994; Papastavros et al., 1986; Soriano, 1997). Apesar de se ter 
Leite, C. A. L.

apenas uma amostra de $P$. indolicus para se avaliar frente ao PRA, se pode sugerir que o resultado encontrado para os antibióticos eritromicina e clindamicina seguiram o padrão ditado por NCCLS (1990) e Reig et al. (1992), que apontaram grande percentual de PRA para ambos as bases antibióticas.

Figura 1 - Concentração inibitória mínima (CIM) a antibióticos selecionados, frente à Peptostreptococcus indolicus isolado do exsudato da bula timpânica de cão da raça São Bernardo (macho, adulto) com otite média bilateral.

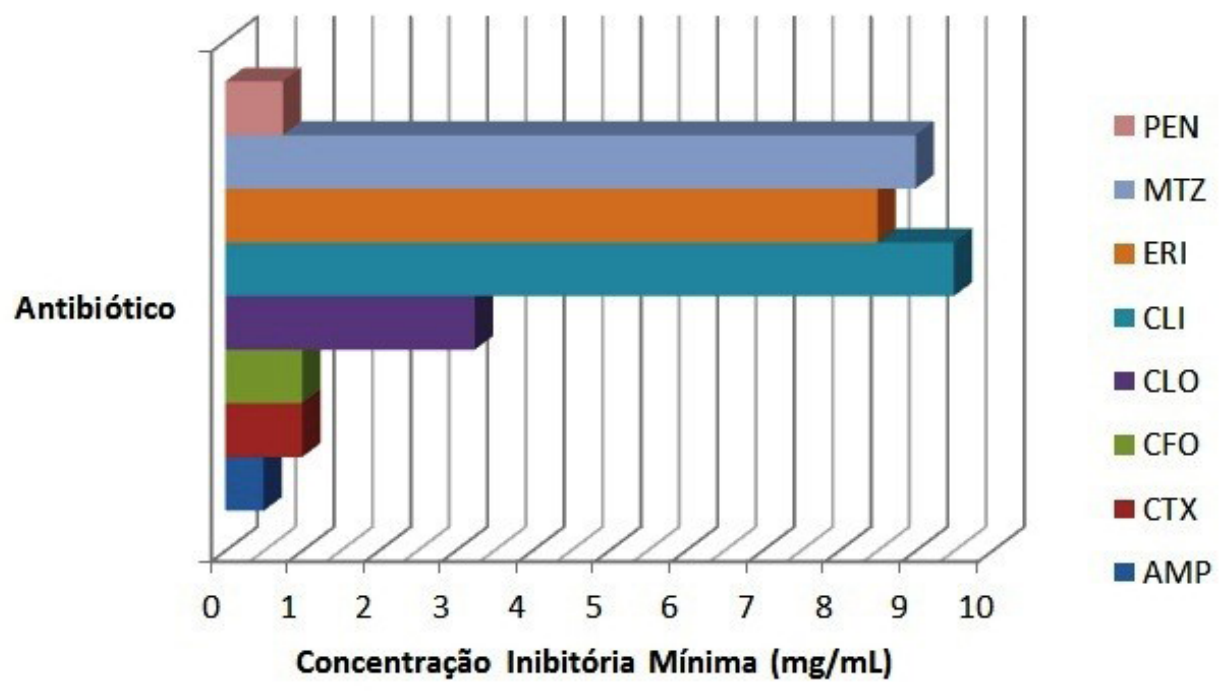

\author{
Ampicilina (AMP) - Cefotaxima (CTX) - Cefoxitina (CFO) \\ Cloranfenicol (CLO) - Clindamicina (CLI) - Eritromicina (ERI) \\ Metronidazol (MTZ) - Penicilina G (PEN)
}

\section{Conclusão}

O isolamento de Peptostreptococcus indolicus da orelha média de cão com otite média crônica sugere que este microrganismo possa ter alguma função na etiologia e desenvolvimento da otopatia, sendo necessária escolha criteriosa do antibiótico a ser utilizado, com preferência para aqueles dos grupos penicilínicos ou cefalosporinícos.

\section{Agradecimentos}

CAPES - Coordenação de Aperfeiçoamento de Pessoal de Nível Superior.

CNPq - Conselho Nacional de Desenvolvimento Científico e Tecnológico.

UFLA - Universidade Federal de Lavras.

\section{Referências}

Amano, E.; Uchida, K.; Ishihara, T.; Otsu, S. Machida, A.; Eishi, Y. Propionibacterium acnes-associated chronic hypertrophic pachymeningitis followed by refractory otitis media: a case report. 2020. BMC Neurology, 20: 1-7. Doi: https://doi.org/10.1186/s12883020-1600-3.

August, J. R. 1988. Otitis externa: a disease of multifactorial etiology. Veterinary Clinics of North America: Small Animal Practice, 18: 731-742. Doi: http://dx.doi.org/10.1016/S0195-5616(88)50076-1.

Brook, I.; Frazier, E. H.; Thompson, D. H. 1992. Aerobic and anaerobic microbiology of external otitis. Clinical Infectious Diseases, 15: 955-958. Doi: http://dx.doi.org/10.1093/clind/15.6.955.

Brook, I.; Van de Heyning, P. H. 1994. Microbiology and management of otitis media. Scandinavian Journal of Infectious Diseases: Supplementum, 93: 20-32. PMID: 8047854.
Brook, I.; Yocum, P; Shah, K. 1998. Aerobic and anaerobic bacteriology of otorrhea associated with tympanostomy tubes in children, Acta Oto-laryngologica. 118: 206-210. Doi: http://dx.doi. org/10.1080/00016489850154919.

Brook, I.; Yocum, P.; Shah, K.; Epstein, S. 1983. Aerobic and anaerobic bacteriologic features of serous otitis media in children. American Journal of Otolaryngology, 4: 389-392. Doi: http://dx.doi.org/10.1016/ s0196-0709(83)80044-1.

Bruyette, D. S.; Lorenz, M. D. 1993. Otitis externa and otitis media: diagnostic and medical aspects: Seminars in Veterinary Medicine and Surgery (Small Animal), 8: 1-9. PMID: 8456201.

Carneiro, L. P.; Rezende, C. M. F.; Silva, C. A.; Laranjeira, M. G.; Carvalho, M. A. R.; Farias, L. M. 2001. External skeletal fixation in dogs: clinical and microbiological evaluation. Arquivo Brasileiro de Medicina Veterinária e Zootecnia, 53: s.p. (on line). Doi: http://dx.doi.org/10.1590/S010209352001000400008. 
Presença de Peptostreptococcus indolicus em bula timpânica de cão com otite média

Cole, L. K.; Kwochka, K. W.; Kowalsky, J. J.; Hillier, A. 1998. Microbial flora and antimicrobial susceptibility patterns of isolated pathogens from the horizontal ear canal and middle ear in dogs with otitis media, Journal of the American Veterinary Medical Association. 212: 534-538. PMID: 9491161.

Colombini, S.; Merchant, S. R.; Hosgood, G. 2000. Microbial flora and antimicrobial susceptibility patterns from dogs with otitis externa. Veterinary Dermatology, 11: 235-239. Doi: http://dx.doi.org/10.1046/ j.1365-3164.2000.00191.x.

Denny, H. R. 1973. The results of surgical treatment of otitis media and interna in the dog. Journal of Small Animal Practice, 14: 585-600. Doi: http://dx.doi.org/10.1111/j.1748-5827.1973.tb06395.x.

Dickinson, A. E.; Rozansky, E. A.; Rush, J. E. 2007. Reversible myocardial depression associated with sepsis in a dog. Journal of veterinary Internal Medicine, 21: 1117-1120. Doi: http://dx.doi.org/10.1892/0891-6640.

Fraser, G.; Withers, A. R.; Spruell, J. S. A. 1961. Otitis externa in the dog. Journal of Small Animal Practice, 2: 1-4. Doi: http://dx.doi. org/10.1111/j.1748-5827.1961.tb04080.x.

Gok, U.; Bulut, Y.; Keles, E.; Yalcin, S.; Doymaz, M. Z. 2001. Bacteriological and PCR analysis of clinical material aspirated from otitis media with effusions. International Journal of Pediatric Otorhinolaryngology, 60: 49-54. Doi: http://dx.doi.org/10.1016/s0165-5876(01)00510-9.

Gotthelf, L. N. 1995. Secondary otitis media - an often overlooked condition. Canine Practice, 20: 14-20. ISSN 1057-6622.

Gotthelf, L. N. 2000. Otitis media. In: Small animal ear diseases: an illustrated guide. 2.ed. W.B. Saunders. Philadelphia. ISBN: 9780721601373.

Griffin, C. E. 2020. Chronic end-stage otitis: treatment and prevention. British Small Animal Veterinary Association Congress Proceedings. p. 105-106, Doi: http://dx.doi.org/10.22233/9781910443774.11.4.

Hillier, S. L.; Moncla, B. J. 2007. Peptostreptococcus, Propionibacterium, Eubacterium, and other nonsporeforming anaerobic Gram-positive bacteria. In: Murray P. R.; Baron, E. J.; Jorgensen, J. H.; Landry, M. L.; Pfaller, M. A. Manual of clinical microbiology. 9.ed. ASM. Washington. ISBN: 9781555813710.

Hnatko, S. I. 1983. Epidemiology of anaerobic infections. Surgery, 93: 125-133. PMID: 6849197.

Husted, J. R. 2003. Bacterial and fungal organisms in the vagina of normal cows and cows with vaginitis. Austin: Texas A\&M University, 22 f. Dissertação Mestrado.

Jokipii, A. M.; Jokipii, L. 1981. Metronidazole, tinidazole, ornidazole and anaerobic infections of the middle ear, maxillary sinus and central nervous system. Scandinavian Journal of Infectious Diseases: Supplementum, 26: 123-129. PMID: 6941449.

Jokipii, L.; Karma, P.; Jokipii, A. M. 1978. Access of metronidazole into the chronically inflamed middle ear with reference to anaerobic bacterial infections. Archives of Otorhinolaryngology, 220: 167-174. Doi: http://dx.doi.org/10.1007/BF00457484.

Kern, L.; Bartmann, C. P.; Verspohl, J.; Rohde, J.; Biernet-Zeit, A. 2016. Bacteraemia before, during and after tooth extraction in horses in the absence of antimicrobial administration. Equine Veterinary Journal, 49: 179-182. Doi: http://dx.doi.or/10.1111/evj.12581.

Koneman, E. W.; Allen, S. D.; Dowell Jr., V. R.; Sommers. H. M. 1979. Color atlas and textbook of diagnostic microbiology. $5^{\text {nd }}$ ed. J.B. Lippincott. Philadelphia. ISBN 10: 0397504055.
Koneman, E. W.; Allen, S. D.; Janda, W. M.; Schreckenberger, P. C.; Winn Jr., W. C. 1994. Introduction to diagnostic microbiology. Lippincott Willians and Wilkins. Philadelphia. ISBN: 0-397-51215-5.

Little, C. J. L.; Lane, J. G. 1989. An evaluation of tympanometry, otoscopy and palpation for assessment of the canine tympanic membrane. The Veterinary Record, 124: 5-8. Doi: http://dx.doi.org/10.1136/vr.124.1.5.

Little, C. J. L.; Lane, J. G.; Pearson, G. R. 1991. Inflammatory middle ear disease of the dog: the pathology of otitis media. The Veterinary Record, 128: 293-296. Doi: http://dx.doi.org/10.1136/vr.128.13.293.

Maggio, C.; Bellezza, E.; Barontini, R.; Bonifazi, L.; Bufalari, A. 2011. Il piotorace nel cane e nel gatto, letteratura umana e veterinaria a confronto. Veterinaria, 5: 19-36. (Doi não encontrado).

Marinho, M.; Meireles, M. V.; Souza, A. V. G. 2004. Determinação da microflora do trato gastrintestinal de avestruzes (Struthio camelus) criados na região noroeste do estado de São Paulo, submetidas à necrópsia. Arquivos do Instituto de Biologia (São Paulo), 71: 267-271. (Doi não encontrado).

Murphy, K. M. 2001. A review of techniques for investigation of otitis externa and otitis media. Clinical Techniques in Small Animal Practice, 16: 236-241. Doi: http://dx.doi.org/10.1053/svms.2001.27601.

National Committee for Clinical Laboratory Standards (NCCLS). 1990. Methods for antimicrobial susceptibility testing of anaerobic bacteria, 2. ed., vol. 9, no. 10. Approved standard M11-A2. National Committee for Clinical Laboratory Standards, Villanova, Pa.

Nwaokorie, F. O.; Nwokoye, N. N.; Chukwu, E. E. 2017. Application of anaerobic techniques in laboratory diagnosis of otitis media in Nigeria: a review. University of Lagos Journal of Basic Medical Sciences, 5: 21-31. ISSN: 2354-4368 (Doi não encontrado).

Papastavros, T.; Giamarellou, H.; Varlejides, S. 1986. Role of aerobic and anaerobic microorganisms in chronic suppurative otitis media. Laryngoscope, 96: 438-442. Doi: http://dx.doi.org/10.1288/00005537$198604000-00017$.

Paterson, S. 2020. Otitis. In: Bruyette, D. S.; Bexfield, N.; Chretin, J. D.; Kidd, L.; Kube, S.; Langston, C.; Owen, T. J.; Oyama, M. A.; Peterson, N.; Reiter, L. v>; Rozanski, E. A.; Ruaux, C.; Torres, S. M. (Ed). Clinical Small Animal Internal Medicine. New Jersey: John Wiley \& Sons. Cap. 167. Doi: https://doi.org/10.1002/9781119501237.ch167.

Paterson, S.; Nett, C.; Neuber, A.; Maddison, J.; Ackerman, N.; Fitzgerald, R.; Noli, C.; Warren, S. 2021. Otitis externa: a roundtable discussion. Companin Animal, 26: S1-S16. Doi: https://doi.org/10.12968/ coan.2021.26.3.S1.

Peng, Y.; Wang, Y.; Hang, S.; Zhu, W. 2013. Microbial diversity in uterus of healthy and metritic postpartum Holstein dairy cows. Folia Microbiologica, 58: 593-600. Doi: http://dx.doi.org/10.1007/s12223013-0238-6.

Reig, M.; Moreno, A.; Baquero, F. 1992. Resistance of Peptostreptococcus spp. to macrolides and lincosamides: inducible and constitutive phenotypes. Antimicrobial Agents and Chemotherapy, 36:662-664. Doi: http://dx.doi.org/10.1128/aac.36.3.662.

Santos, P. K. B.; Carniatto, C. H. O.; Anizelli, A. C.; Petry, F. L. B.; Verlingue, G. F.; Zavatine, F. 2019. Estomatite em felinos domésticos: revisão. In: XI Encontro Internacional de Produção Científica. 2019. 4 f. (anais eletrônico). Disponível em: < http://rdu.unicesumar.edu.br/ handle/123456789/4137>. 
Leite, C. A. L.

Shuiquan, T.; Prema, A.; Tjokrosurjoa, J.; Sarya, M.; Van Bela, M. A.; Rodrigues-Hoffmannb, A.; Kavanaghc, M.; Wua, G.; Van Edena, M. E.; Krumbecka, J. A. The canine skin and ear microbiome: A comprehensive survey of pathogens implicated in canine skin and ear infections using a novel next-generation sequencing-based assay. 2020. Veterinary Microbiology, 247: 1-10. Doi: https://doi.org/10.1016/j. vetmic.2020.108764.

Silva, B. P. 2018. Avaliação microbiológica de abscessos hepáticos de bovinos abatidos em um abatedouro frigorífico localizado na região do Semiárido Nordeste II da Bahia. $46 \mathrm{f}$. Cruz das Lamas: Universidade Federal do Recôncavo da Bahia. Dissertação Mestrado Profissional. Disponível em: <http://localhost:8080/handle/prefix/1042>.

Soriano, F. 1997. Microbial etiologies of acute otitis media. Clinical Microbiology and Infection, 3: 3S22-3S25. Doi: http://dx.doi. org/10.1016/S1198-743X(14)64948-X.
Trower, N. D.; Gregory, S. P.; Renfrew, H.; Lamb, C. R. 1998. Evaluation of the canine tympanic membrane by positive contrast ear canalography. The Veterinary Record, 142: 78-81. Doi: http://dx.doi.org/10.1136/ vr.142.4.78.

Valdez, L. A.; Vallejo, A. A. 2020. Identificación microbiológica en enfermedades gingivo-periodontales en perros atendidos en el Consultorio Veterinario El Fortín. Guayaquil: Universidad de Guayaquil, 93 f. Trabalho de Conclusão de Curso de Graduação em Medicina Veterinária. Disponível em: <http://repositorio.ug.edu.ec/handle/ redug/49134>.

Wilkins, T. D.; Thiel, T. 1973. Modified broth-disk method for testing the antibiotic susceptibility of anaerobic bacteria. Antimicrobial Agents and Chemotherapy, 3: 350-356. Doi: http://dx.doi.org/10.1128/ AAC.50.1.1-21.2006. 